from the National Heart Hospital:13 " One can only be guarded about the long-term prognosis, and centres looking for a new form of aortic valve replacement should not be guided by initial favourable reports."

1 Senning, A, Acta Chirurgica Scandinavica, 1966, suppl no 356B, p 17. 'Senning, A, fournal of Thoracic and Cardiovascular Surgery, 1967, 54, 465.

${ }^{3}$ Flege, J B Jr, et al, Fournal of Thoracic ard Cardiovascular Surgery, 1967, $54,222$.

4 Gilbert, F W Jr, et al, Archives of Surgery, 1968, 97, 149.

${ }^{5}$ Myers, W O, and Miller, D R, Fournal of Thoracic and Cardiovascular Surgery, 1969, 57, 805.

${ }^{6}$ Ioenscu, M I, and Ross, D N, Lancet, 1969, 2, 335.

' Edwards, W S, et al, fournal of Thoracic and Cardiovascular Surgery, 1969, 58,854 .

${ }^{8}$ Ioenscu, M I, et al, Thorax, 1970, 25, 46

${ }^{9}$ McEnany, M T, Ross, D N, and Yates, A K, fournal of Thoracic and Cardiovascular Surgery, 1972, 63, 199.

10 Senning, A, and Rothlin, M, Vascular Surgery, 1973, 7, 29.

11 Petch, M, et al, British Heart fournal, 1974, 36, 177.

1: Mary, D A S, et al, British Heart fournal, 1975, 37, 1123.

${ }^{13}$ Joseph, S, et al, British Heart fournal, 1974, 36, 760.

${ }^{14}$ Senning, A, discussion of paper by Ioenscu, M I, et al, fournal of Thoracic and Cardiovascular Surgery, 1974, 68, 379.

15 Trimble, A S (ed), Surgery, 1972, 71, 10.

16 Silver, M D, Hudson, R E B, and Trimble, A S, fournal of Thoracic and Cardiovascular Surgery, 1975, 70, 360.

17 Olsen, E G J, et al, Thorax, 1975, 30, 528.

18 Trimble, A S, et al, fournal of Thoracic and Cardiovascular Surgery, 1974, $68,219$.

19 Ioenscu, M I, et al, fournal of Thoracic and Cardiovascular Surgery, 1974, 68,361 .

\section{Getting postgraduate education right}

A doctor must learn throughout his working life, not simply to keep abreast of the growth of medical knowledge but also to cope with the gradual changes in the patterns of practice and in the expectations of patients. Some haphazard continuing education is inevitable from the information with which doctors are bombarded from all sides. They also have access to many sources of reference, but even so their clinical performance is often limited by lack of knowledge and skills. Within the last decade there has been wider recognition of the deficiencies in the current system, and doctors have begun to set up formal programmes to promote their own continuing education. ${ }^{1}$ Hospital doctors have the best opportunitiesfrequent contact with colleagues and ward rounds, clinical meetings, and meetings of specialist societies help to keep them up to date. Nevertheless, similar facilities are now being provided for general practitioners; they have been encouraged to attend courses and to use the postgraduate centres which have been established all over the country.

Presumably these programmes arranged for general practitioners are meant to improve the quality of their day-to-day work, but there must be serious doubts whether this goal has been achieved by the formal presentations organised at most postgraduate centres ${ }^{12}$-though they certainly do play a valuable part in providing library facilities and opportunities for contact between colleagues. Formal programmes may fail for several reasons. Firstly, the intended learner-the general practitioner-is often absent when the content of the programme is decided. Secondly, the subject matter which can be covered, even over a year or two, is necessarily limited and may make little difference to the doctor's daily practice.
Thirdly, and perhaps most important, the programmes usually take the form of lectures or panel discussions during which experts transmit information to a passive audience; this violates the sound educational principle that learners should be active participants in the educational process.

Cole and Engel have recently advocated a different approach, ${ }^{3}$ illustrated by their attempts to improve the standard of care given by general practitioners to children with heart disease. They set out in detail the knowledge and skills which the individual doctor should have, or would have to acquire, in order to meet the standards they thought necessary. Their booklet is a commendable attempt to outline the requirements for a course for general practitioners, and those interested in the technical aspects of medical education should study it.

Unfortunately the scheme is detailed and demanding, and it is unlikely that their objectives could be met even for this small area of general practice. Probably any attempt to extend their approach to broader aspects of general practice would be doomed to failure, since their format might discourage or even alienate general practitioners. But they did emphasise one very important principle: that each practitioner should examine their list of objectives and identify his own educational needs. This is surely right. The educational requirements of individual doctors must vary widely; for this reason, if for no other, the continuing education of the doctor must be continuing self-education and not continual instruction. The problem is to help him identify his needs and then to help him satisfy them.

If continuing education aims at helping the doctor to look after his patients, then improvement in the quality of the care he provides must depend not only on detecting gaps in his knowledge but also on identifying deficiencies in the care given to them. To identify these deficiencies the doctor needs feedback on his own performance and that of his medical team. Such feedback could come from his personal evaluation using predetermined standards, from peer review, or from the comments of his practice staff and his patients. As yet, unfortunately, the idea of such evaluation remains foreign to most British doctors, for whom audit is either a mystery or a dirty word. It would be reasonable to resist audit if it were to be used punitively, but surely there can be few sound arguments against its educational use.

At present there is little likelihood that many doctors will review their own performance carefully and critically to determine their educational needs. Such action requires a change in attitude, which will not occur spontaneously and will not result from exhortations, whether from "super-docs" or from the DHSS. Attitudes of this kind need to be vigorously promoted and their seeds must be sown as early as possible. It is in our medical schools that the process must begin. ${ }^{4}$ Students must learn to recognise the limitations of their own knowledge and abilities, and to admit their areas of ignorance. The attitudes which they develop to independent learning must ensure continuing self-education so that they can adapt to the constant changes in medical practice. At present we do not promote these qualities in our students: this is the greatest indictment of our present system of medical education.

\footnotetext{
${ }^{1}$ Anglo-American Conference on Continuing Medical Education, eds C L Joiner and G E Paget. London, Royal Society of Medicine, 1974.

${ }^{2}$ Libby, G N, Weinsweg, M H, and Kirk, K W, fournal of the American Medical Association, 1975, 233, 797.

3 Cole, R B, and Engel, C E, Planning a Course of Continuing Education For General Practice-A Systematic Approach. London, Council for Educational Technology, 1975.

${ }^{4}$ Beaton, G R, British Fournal of Medical Education, 1974, 8, 145.
} 